\title{
En busca de la calidad académica
}

\section{Reseña elaborada por:}

MónICA MÁRQuez HERMOSILlo*

LUIS MARRUFO CARDÍN**

Libro: En busca de la calidad académica, de Catherine Paradeise y Jean-Claude Thoenig (trad. Marcela Pimentel). México: Fondo de Cultura Económica, col. Educación y Pedagogía, 2017

$\mathrm{S}$ i del estado del arte en el campo de las universidades se trata, tanto en el orden local como global, la voz de Catherine Paradeise y de Jean Claude Thoenig resulta ineludible. Tendencias, reformas, actores, políticas educativas, modelos teóricos, organizacionales y evaluativos, gobernanza e impacto en las estructuras sociales son focos de interés que han nutrido su amplia trayectoria de investigación.

Un arduo y consistente trabajo está detrás de este libro: En busca de la calidad académica. Anteriores acercamientos publicados por Paradeise y Thoenig, siempre desde una perspectiva social, han mostrado cómo el campo de la educación superior se está remodelando. En esta obra, que en inglés salió a la luz en 2015, pero que es traducida hoy al español por Marcela Pimentel, a través del Fondo de Cultura Económica, se nos muestra con mayor profundidad un análisis de lo que es, y una proyección de lo que puede llegar ser, la universidad del siglo XXI.

Quienes trabajamos en el campo de la educación superior somos testigos de la recurrencia del tema de la calidad académica y de cómo, en ocasiones, esta aspiración ha resultado una ilusión evasiva que se escapa a quien pretende perseguirla o que se presenta tirana y altiva ante quien ha buscado atraparla. Aun cuando el foco de este estudio se ubica geográficamente en América del Norte y Europa, para otros contextos los resultados de su investigación constituyen una valiosa señalética.

La obra resulta un ingrediente clave para reflexionar sobre lo que supone una búsqueda de esta naturaleza. Sus autores, Catherine Paradeise y Jean-Claude Thoenig, proponen una ruta inteligente para incursionar en el tema, ya que, en sus palabras, "este libro proporciona lentes: una serie de paquetes de herramientas analíticas y redes conceptuales para dar sentido a las tendencias en curso, con el fin de evitar dos extremos: [por un lado la] simplificación excesiva y [por otro la] confusión".

Contar con estos marcos conceptuales resulta en particular importante para quienes han de tomar decisiones dentro del ámbito de la vida universitaria, ya que, desde esta perspectiva, no basta con una declaración de principios sobre la innovación, los liderazgos o la calidad educativa; es preciso saber observar a la organización como sistema y partir del tipo de relaciones presentes y ausentes en el tejido institucional. Esto, en términos de gobernanza, supone un mundo complejo de consideraciones.

Recibida: 5 de diciembre de 2017. Aceptada para su publicación: 28 de junio de 2018. DOI: $10.31391 / S 2007-7033(2018) 0051-013$

* Doctora en Innovación Educativa con especialidad en Literacidad. Coordinadora de la academia de Ética, Identidad y Profesión del Departamento de Formación Humana de ITESO. Directora académica de la asociación Letra Uno, Proyectos de Lectura, AC. Sus líneas de investigación son la innovación educativa, la literacidad y la tecnología educativa. Correo electrónico: mmarquez@iteso.mx

** Doctorado en Filosofía de la Educación. Profesor del Departamento de Formación Humana del ITESO. Sus áreas de interés son la filosofía moral y el diálogo intercultural. Correo electrónico: lmarrufo@iteso.mx 
Los autores comienzan esta aventura planteando cuatro tendencias que han favorecido la proliferación de universidades por todo el mundo: la masificación, la globalización, la mercantilización y la estandarización. Estas cuatro tendencias han representado el factor clave para la elaboración de políticas públicas y para la regulación de los estándares académicos vigentes en el mundo.

Resulta enriquecedor, en primer lugar, el abordaje histórico que los autores presentan para ilustrar el proceso de masificación de la educación terciaria y las políticas públicas que lo han acompañado, tanto en los países del primer mundo como en las economías emergentes. En segundo lugar, aporta su visión crítica ante las tendencias de mercantilización de la educación superior y de la investigación, realidad que ha reforzado la idea del valor de mercado de los grados otorgados por las universidades, como un camino hacia la movilidad social ascendente.

Su detallado y riguroso análisis nos muestra cómo esta tendencia enmarca las formas en que la calidad académica se evalúa, se juzga y se valora hoy, y explora, históricamente, lo que la aparición de clasificaciones, índices y rankings han propiciado: por un lado, la tendencia a la mejora en ciertos indicadores que favorecen la calidad académica, aunque, por otro, resulte contradictorio realizar una comparación equitativa de ofertas en un mercado homogéneo en forma artificial. En ciertos casos, el afán competitivo también ha originado que algunas instituciones realicen prácticas desleales y de simulación con el afán de obtener recursos económicos o de subir con simulación los puntajes globales, sin que esto se traduzca en una mejora real.

Sin embargo, ¿qué es lo que las universidades están haciendo ahora para producir calidad académica? Paradeise y Thoenig proponen dos elementos clave para entender el camino de la búsqueda: el primero es la reputación de la universidad y el segundo, la llamada excelencia. A partir de la forma en que las universidades se posicionan respecto a estas dos claves, los autores desarrollan una matriz que define cuatro categorías o tipos ideales de instituciones: misioneras, venerables, aspirantes y excelsas.

Las universidades misioneras se caracterizan por atender a su propia misión institucional, con una visión muy específica de la calidad; las venerables se sostienen en una reputación histórica; las aspirantes viven en constante esfuerzo por cumplir con los requisitos definidos por las clasificaciones internacionales en cuanto a la medición de la calidad; y las excelsas gozan de prestigio por su excelencia y, ubicadas en el top del ranking, constituyen por ello la élite.

Utilizando el marco conceptual y metodológico de la sociología organizacional, la investigación examina en detalle los procesos sociales que se dan en cada tipo de universidad, y concluye que no son las fuerzas globales de la economía, la cultura o las políticas públicas las que determinan la evolución de las universidades. Aunque los mercados laborales, las fuentes de financiación, las políticas nacionales y la competencia internacional ejercen una fuerte presión, "todavía hay mucho espacio para la diversidad y una libertad significativa de elección".

Aunque las reformas a las políticas de educación superior y de investigación se diseñen a partir de un marco de éxito uniforme basado en indicadores para la excelencia, el poder de la microgestión y de decisión de las universidades en términos de organización, finanzas, gestión de recursos humanos y libertad académica al final 
queda en las universidades. Este grado de autonomía crece cuando se orienta por criterios explícitos, coherentes y contextualizados, más allá de principios abstractos generales y suposiciones sobre la eficiencia, la autoridad o la calidad.

Mucho más allá de la retórica de la globalización y la excelencia, En busca de la calidad académica nos muestra que cada universidad es "un sistema social colectivo complejo que se define como un orden local que reacciona específicamente a los cambios en los recursos y las limitaciones generadas por su entorno".

Un ingrediente crucial para alcanzar la calidad es una gran capacidad institucional para adaptarse con iniciativa a los nuevos requerimientos y a los cambios en su entorno; es decir, funcionar como un sistema social y organizacional que combine "la homogeneidad y la homeostasis" en un estado de equilibrio, "aplicando una serie de procesos autorregulados-relacionados con propiedades organizacionales".

Además, una serie de procesos sociales y factores informales, pero sumamente relevantes, son los que ayudan a sostener la sólida y estable estructura institucional de las universidades excelsas, entre ellos: una visión compartida del bien común y de su contribución a la sociedad, un sentido de ciudadanía, compromiso, receptividad y confianza recíproca, lo cual "constituye un todo extremadamente complejo cuya emulación requeriría años y un entorno de políticas de apoyo".

La pregunta para cada universidad es: dar el giro hacia la excelencia, ¿favorece o va en contra del servicio educativo que busca ofrecer? El libro de Catherine y Jean-Claude impulsa a repensarnos como universidad y a disponernos a hacer cambios profundos tanto en la concepción misma de la educación superior como de sus funciones. Cada universidad habrá de definir la excelencia en sus propios términos. No hay un solo modelo que funcione para todos, sino muchos tipos diferentes de excelencia.

La cultura de rendición de cuentas, de los indicadores de desempeño "objetivos", analíticos y estandarizados, nos han invadido. Con un estilo sobrio y sumamente accesible, los dos autores analizan esta realidad y nos ofrecen un posible espejo, no en términos abstractos ni en tono prescriptivo, sino caracterizando a la universidad como el constructo colectivo que es, que se mueve, que respira. 